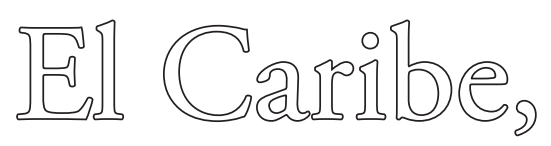

\title{
Según Pedro Ureña Rib y Jean-Paul Duviols
}

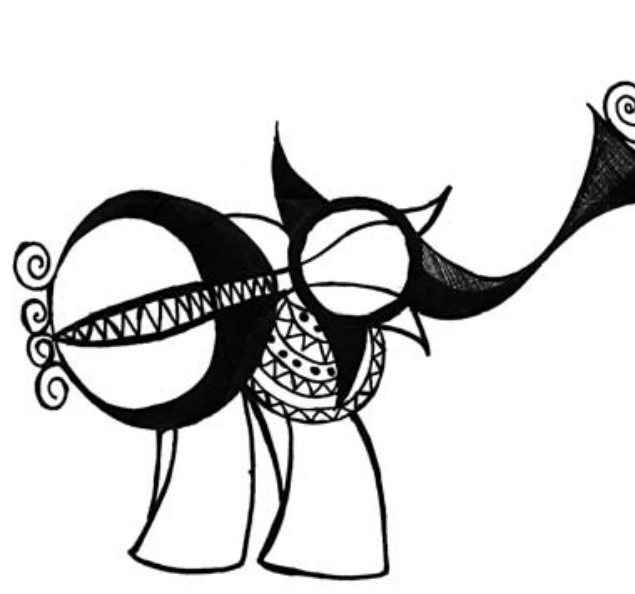

\section{Resumen}

El presente artículo es una breve aproximación de un fecundo diccionario que contiene un cúmulo de información de múltiples ámbitos: históricos, geográficos, sociales, étnicos, lingüísticos, literarios, artísticos, etc. Se ha intentado extraer del diccionario información que guíe al lector peruano sobre los aspectos más importantes del conocimiento de ese conglomerado de países que en nuestro medio se denomina genéricamente "El Caribe", y que en la actualidad prácticamente se limita a la información que ofrecen los diarios sobre cuestiones políticas. Previamente, se realiza un sucinto recuento del conocimiento de algunos aspectos (literarios, históricos, etc.) que han marcado el interés o la atención en nuestro medio en décadas anteriores.

Palabras clave: diccionario histórico-geográfico, cultura caribeña, tradición popular, Las Antillas.

\begin{abstract}
The present article is a brief closeness of a fruitful dictionary that contains a heap of information about numerous fields: historical, geographic, social, ethnical, linguistic, literary, artistic, etc. It has been tried to draw from the dictionary information that guides the Peruvian reader through the most important knowledge aspects of this conglomeration of countries that in our surroundings it is generically denominated El Caribe, and that currently it is practically limited to the information offered by newspapers about political matters. Previously, a succinct recount is performed, about the knowledge of some aspects (literary, historical, etc.) that have marked the interest or attention in our surroundings in previous decades.
\end{abstract}

Keywords: historical-geographic dictionary, Caribbean culture, popular tradition, The Antilles.

\author{
Por: Roberto Reyes Tarazona \\ Universidad Ricardo Palma \\ rreyes@urp.edu.pe
}

Caribe, título general del libro de Pedro Ureña y JeanPaul Duviols, es un diccionario cuyo contenido se define en el complemento del título: Sus intelectuales, sus culturas, sus artistas, su historia, sus tradiciones populares (2014).

Con esta referencia, se puede prever un trabajo de recopilación, ordenamiento y unificación de conceptos y definiciones en torno a un tema central, en este caso el Caribe, como es usual en un diccionario. Pero, en el presente caso, es mucho más que una labor taxonómica.

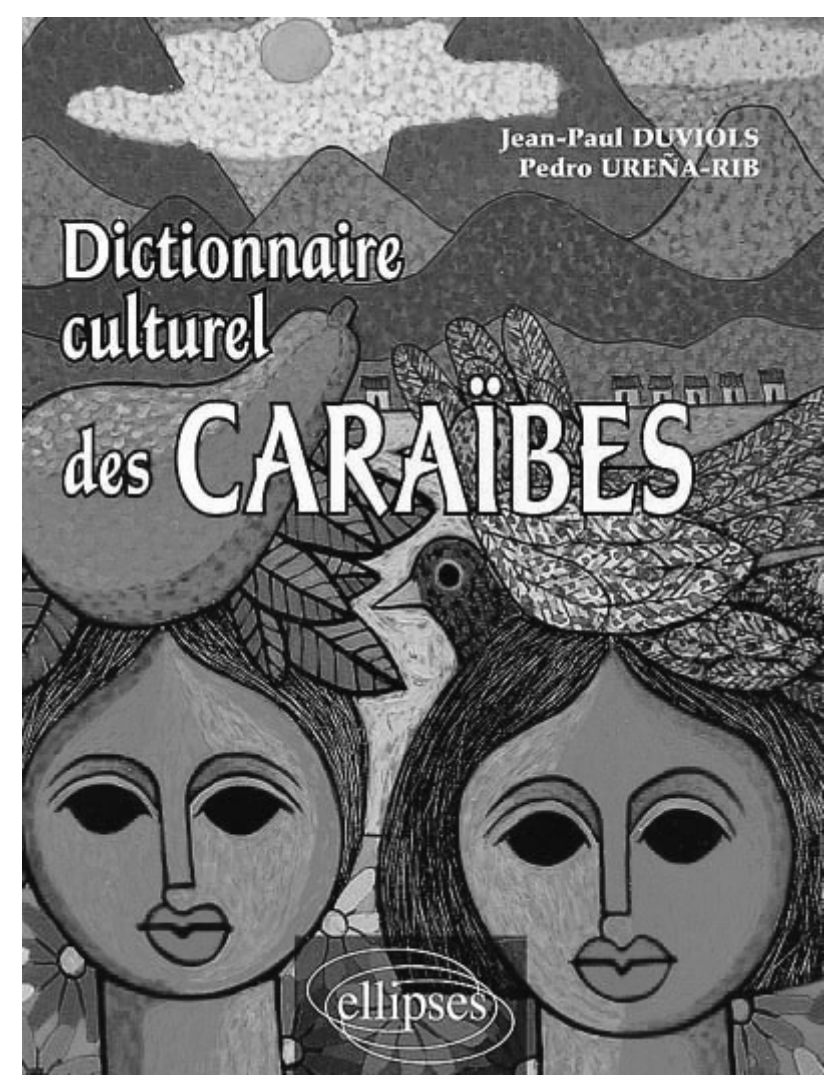


En principio, sobre el tipo de diccionario ofrecido por estos dos intelectuales, en nuestro país encontramos algunos trabajos afines. Por remitirnos a antecedentes de referencia obligados, mencionaremos el Diccionario histórico-geográfico del Perú, de Mariano Felipe Paz Soldán, publicado en 1877 y el Diccionario geográfico peruano, de Germán Stiglish, de 1922. Más cercanos son dignos de recordar el Diccionario Enciclopédico del Perú, editado por Juan Mejía Baca en 1975 y el Diccionario Histórico y Biográfico del Perú, editado por Carlos Milla Batres en 1986. En un ámbito de nivel regional o departamental, entre los muchos diccionarios escritos a lo largo del siglo veinte, es ejemplar el Diccionario Geográfico e Histórico de Cajamarca, de Carlos Burga Larrea, publicado en 1983.

En un contexto extranacional y propio de ese siglo, aunque con una concepción acorde con supuestos teóricos recientes, podemos mencionar al Diccionario de Estudios Culturales Latinoamericanos. Este diccionario responde a un enfoque multidisciplinar producto de la nueva perspectiva de acercamiento a la realidad social, el correspondiente a los estudios culturales, en los que se conjugan fundamentos teóricos y prácticas metodológicas de las ciencias sociales, la filosofía y las humanidades.

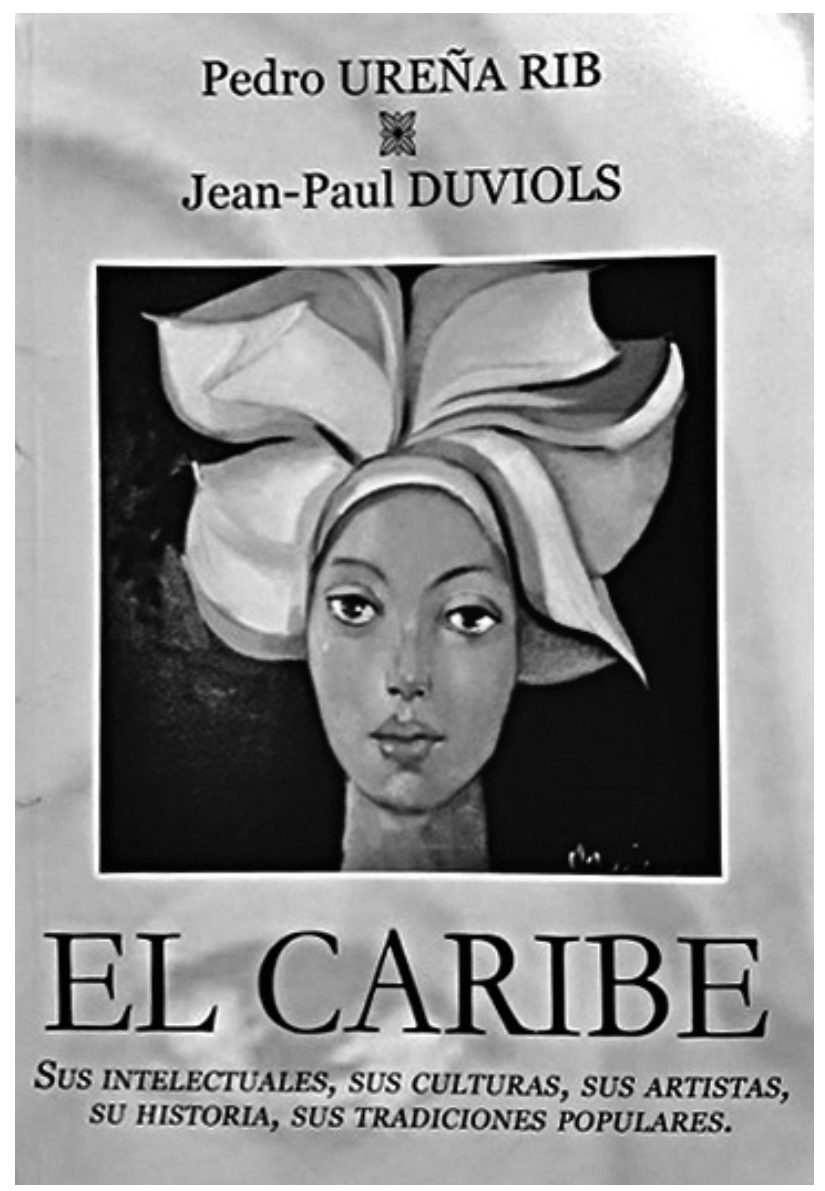

El diccionario sobre el Caribe que comentamos en esta ocasión, comparte gran parte de las características de los casos antes mencionados, aunque de una manera sui géneris. Por un lado, es un diccionario que podríamos denominar "de autor", es decir, producto de la concepción, conocimientos y visión del tema de sus creadores, gracias a su formación, sus experiencias personales y su preocupación por un asunto que consideran importante; y, por otro lado, es un diccionario hasta cierto punto enciclopédico, el cual por lo general es realizado por una institución o un equipo, o equipos, de especialistas.

En relación al tema, es decir, el Caribe, me permito apuntar algunas consideraciones básicas sobre su conocimiento en nuestro país. Al respecto, no existe en nuestro medio un estudio que haya revelado en profundidad y de manera sistemática qué tanto conocemos acerca de un universo cultural tan cercano pero a la vez tan desconocido. Por tanto, limitándome a la esfera intelectual y académica de la segunda mitad del siglo veinte, para reducir el ámbito social y temporal a una dimensión asequible, pondré en consideración algunas ideas preliminares, esbozos de datos a partir de acontecimientos evidentes, principalmente desprendidos de su tratamiento en los medios de comunicación masiva y de su difusión basada en productos editoriales.

El mayor y más amplio nivel de conocimiento de los hechos relacionados con el Caribe proviene de la política, principalmente cuando la prensa focaliza las noticias de mayor impacto. El principal hecho político fue la Revolución Cubana, que puso al Caribe en primera plana mundial durante más de dos décadas, rebasando en esta etapa el circuito de la prensa y de lo político para derivarse a otras esferas del quehacer social y cultural. Le siguen en conocimiento general, las intervenciones del imperialismo norteamericano a Cuba (Bahía de Cochinos), República Dominicana, Granada, etc.; derrocamiento de dictadores, así como otros hechos políticos impactantes que irradiaron interés continental.

Dejando aparte este nivel, a fin de centrarnos en la historia social y cultural caribeña, para los estudiantes de ciencias sociales en los años sesenta era imprescindible la lectura y discusión del libro del escritor martiniqués Franz Fanon Los condenados de la tierra. En el contexto de los años de las luchas por la descolonización de África y Asia, sus propuestas sobre la liberación colonial, se articulaban con argumentos desprendidos de la historia de la esclavitud y de las condiciones de 


\section{《El mayor y más amplio}

\section{nivel de conocimiento de los}

hechos relacionados con el

Caribe proviene de la política, principalmente cuando la prensa focaliza las noticias de mayor impacto.

racismo y marginación étnica subsistentes, lo cual le daba un nuevo significado a la teoría marxista de las luchas antiimperialistas. A raíz de la lectura y discusión del libro de Fanon, se desprendió el interés por conocer qué era el movimiento de la negritud, cuáles eran sus fundamentos y propuestas, en las que destacaban Aimé Césaire, Nicolás Guillén y Leópold Sédar Senghor, intelectuales y poetas.
En 1962, la llegada de Juan Bosch en el contexto de la campaña electoral para la elección presidencial peruana, atrajo la atención de los comentaristas políticos sobre la situación de su país y las circunstancias que se vivían por entonces en el Caribe en general. Una década después, un intelectual dominicano, Pablo Mariñes, durante su estadía de año y medio en el Perú, dictó un curso sobre cultura caribeña a los alumnos de antropología de la Universidad Nacional Mayor de San Marcos. Durante el desarrollo de su cátedra, facilitó a los estudiantes acceso a material desconocido en nuestro medio sobre el tema, lo cual estimuló algunas investigaciones posteriores de los participantes de aquel seminario.

En el ámbito literario, es inevitable referirse a la obra de Alejo Carpentier, principalmente por la amplia difusión que tuvo su narrativa, y, para el caso que nos ocupa, particularmente de El reino de este mundo y El siglo de las luces, que puso ante los ojos y la mente de los peruanos y latinoamericanos en general hechos de la historia de Haití, de la negritud, de las luchas por su independencia, además de la presencia de las creencias

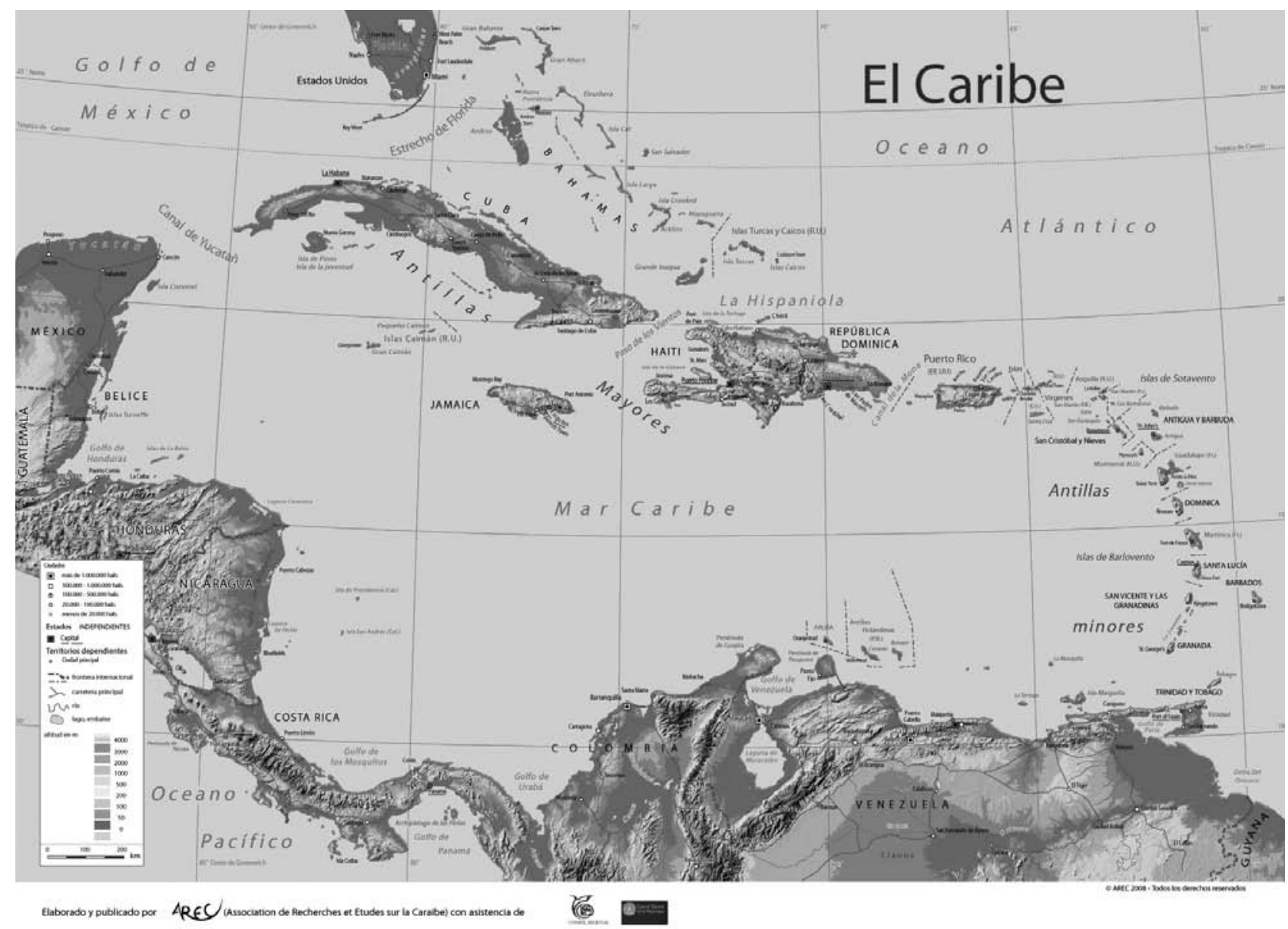


y prácticas relativas al vudú y otras expresiones de la cultura africana que, en el caso de nuestro país, rozaban con algunas formas y expresiones propias.

A partir de los ańos sesenta, la editorial de Casa de las Américas de Cuba, además de la revista del mismo nombre que acogía la producción ensayística y literaria de América Latina y el Caribe, empezó a revelar al público latinoamericano, ávido de conocimiento de la obra de escritores con los cuales compartíamos rasgos comunes pero que solo conocíamos de nombre, o definitivamente nos eran desconocidos, libros de creación literaria caribeńa caracterizados por su originalidad y aliento. Antes de la gran labor editorial de esta institución, los escritores caribeńos, aparte de las novelas y cuentos de algunos cubanos, difundidos principalmente gracias al interés que despertó en toda América Latina su revolución, eran escasamente conocidos en ella.

Los escritores caribeños más conocidos por entonces eran Alejo Carpentier y Nicolás Guillén. A ellos se podía sumar Juan Bosch, quien aparecía en todas las antologías latinoamericanas del cuento. Otros autores eran publicados circunstancialmente en editoriales de países latinoamericanos. Algunos ejemplos: Puerto Limón, de Joaquín Gutiérrez y Mamita Yunai, de Carlos Luis Fallas, en Chile; Batuala, de René Marán

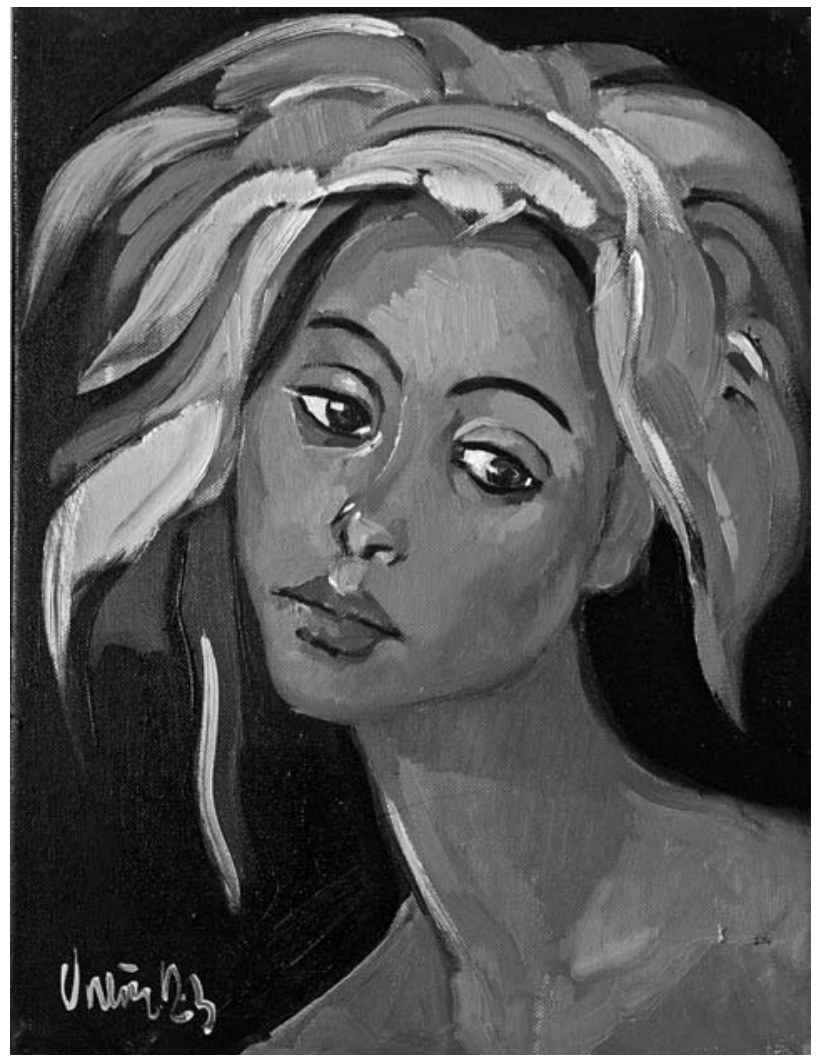

En el diccionario, el principal recurso para acercarse al complejo entramado de cambios y acciones políticas, se encuentra en los apartados referidos a los países del área, cuyo contenido incluye siempre los hechos y acciones históricas que dieron lugar a su formación como estado.

y El curandero mistico, de V. S. Naipaul, en Argentina; El hombre que trabajó el lunes de Emilio Díaz Valcárcel y En un abrir y cerrar de ojos de Jacques Stephen Alexis, en México.

Estos y otros títulos más, aparecían de manera esporádica; en cambio, Casa de las Américas de Cuba, en su colección Literatura Latinoamericana, entre los años setenta y ochenta, entregó a la comunidad del continente muchas obras de la literatura caribeña. De la larga lista, baste mencionar unos cuantos a manera de muestra: Las montañas jubilosas, de Roger Mais; Gobernadores del rocio, de Jacques Roumain; Midas negro, de Jan Carew; La isla mágica, de Rogelio Sinán; El vasto mar de los sargazos, de Jean Rhys; Cuentos del Caribe. Barbados, Guyana, Jamaica, Trinidad-Tobago, selección de Blanca Acosta, Samuel Goldberg e Ileana Sanz.

Dejando atrás estas consideraciones preliminares y antecedentes, que muestran el muy limitado conocimiento de la cultura caribeña en nuestro medio, el libro de Pedro Ureña y Jean-Paul Duviols ofrece un panorama de un caudal imposible de asimilar y sistematizar en una sola aproximación, como la que he podido realizar. Sin embargo, quisiera destacar algunos rasgos esenciales de la riqueza de este libro y arriesgar unas pocas ideas producto de su lectura.

En los aspectos históricos y geográficos, campos esenciales del contenido de muchos diccionarios culturales, el conocimiento del Caribe en nuestro medio es, al menos en sus líneas generales, más consistente en lo histórico, en tanto que desde el nivel escolar se sabe que Colón llegó a las islas de esta 
región, y que existían diversas etnias nativas. En ellas se fundaron las primeras ciudades y se establecieron las primeras colonias. En torno a ello, se conocen las más llamativas peripecias de los conquistadores españoles. De manera que lo ofrecido por el diccionario amplía y precisa el conocimiento de los hechos históricos de lo que se ha dado en llamar el descubrimiento de América, en mayor o menor medida familiares para nosotros.

De igual manera, respecto al desenvolvimiento de la piratería y el filibusterismo de los siglos inmediatos, fenómeno del que no estuvimos ajenos en el virreinato, pero que ha sido aureolado y distorsionado por la leyenda y la ficción en múltiples formas, en el diccionario se ofrecen datos y precisiones que permiten distinguir la realidad de la ficción.

Curiosamente, para nosotros, a medida que avanzan los siglos, el conocimiento de la historia de los países y territorios que conforman el Caribe se hace más difuso, en tanto que va a sufrir la acción colonialista de Inglaterra, Francia, Holanda $y$, por supuesto, España, en diversa medida, dando lugar a cambios de posesión y organizaciones políticas de las más diversas formas. En el diccionario, el principal recurso para acercarse al complejo entramado de cambios y acciones políticas, se encuentra en los apartados referidos a los países del área, cuyo contenido incluye siempre los hechos y acciones históricas que dieron lugar a su formación como estado. Ya en el siglo veinte, complementan estas reseñas históricas las biografías de destacados personajes, no necesariamente ejemplares. Aquí, nuevamente, encontramos actores políticos de alguna manera familiares incluso para los lectores de información media. Por ejemplo, Jacobo Arbenz, Juan Bosch, Francois Duvalier, Fidel Castro, Ernesto "Che" Guevara, Sandino, Anastasio Somoza, Rafael Trujillo, y muchas figuras políticas más.

En el aspecto geográfico, en cambio, el diccionario de Ureña y Duviols revela la extraordinaria variedad de espacios que constituyen el Caribe, con seguridad conocidos por muy pocas personas en nuestro medio. Resaltan, para los no iniciados, como quien escribe estas líneas, en principio, la distinción entre el Caribe y las Antillas, que por lo general son tratados como sinónimos. Asimismo, de manera didáctica, se exponen las conformaciones dentro de esta última: las islas Lucayas y Bahamas, las Antillas Mayores y las Antillas Menores; y, por si fuera poco, las islas de Barlovento y las Islas de Sotavento. En total, suman una enorme cantidad de islas, independientes, o integrantes de los países que constituyen estos conglomerados. Semejante complejidad explica en gran medida también la extraordinaria cantidad de expresiones culturales que se van registrando a lo largo del libro, producto de la relación entre los grupos étnicos nativos, los descendientes de esclavos provenientes de distintas regiones del África y la población europea y mestiza, en un proceso de diferenciación, hostilidad o sincretismo, incesantes. Por mencionar algunos casos, nos encontramos con los siboney, los arahuaco, los gabilis, los kuna, los palikurs, los taínos, los garífunas, los miskitos, etc.

Estos dan como resultado una inagotable riqueza de expresiones en algunos ítems culturales, como por ejemplo la gastronomía, los carnavales, el cine; además de la diversidad de creencias, prácticas y deidades en torno a lo sobrenatural, como vudú, ciguapas, galipotes, santería, hounsi, ochún, ogún, etc. Demás está decir que este es uno de los puntos más subyugantes para los lectores ávidos del conocimiento de lo distinto, de lo diferente.

Semejante riqueza, explica de alguna manera, conjeturo, la gran cantidad de destacados etnólogos, antropólogos y científicos sociales en general que se registran en el diccionario, a diferencia de lo que se puede encontrar en los diccionarios de nuestro país, en el cual sobreabundan los hombres de leyes, que además de la política incursionan en otras expresiones intelectuales, como la historia, el periodismo y el ensayo social. Además, los intelectuales caribeños, por lo que se puede leer, son muy proclives a incursionar en la creación literaria, produciendo obras que, de acuerdo a lo reseñado por los autores del diccionario, ofrecen mundos narrativos de gran originalidad e interés, lamentablemente desconocidos en nuestro medio.

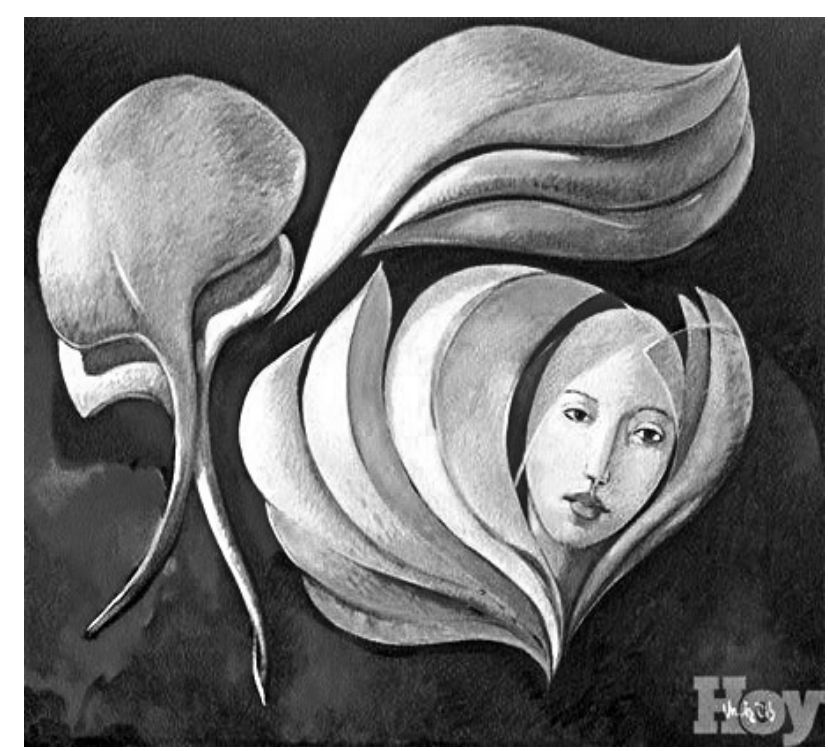


Otro rasgo digno de mención es la alternativa adoptada por los autores del libro de incorporar en su trabajo tanto expresiones de ritmos musicales del pasado y del presente como compositores e intérpretes de música popular. Así podemos encontrar espacios dedicados al areíto, al bolero, a la bachata, al calypso, al cha-chacha, al danzón, a la cumbia, etc., y a Beny Moré, Rubén Blades, Celia Cruz, Willy Chirino, Xavier Cugat, Mongo Santa María, Rolando Lasérie, entre muchos otros músicos.

La literaturay sus exponentes constituyen un componente fundamental en el diccionario, pero ese es un tema que debe tratarse de manera particular, por su amplitud y riqueza, de modo que solo diré que la selección y la precisión con que se exponen los temas abordados por los creadores caribeños, sus méritos artísticos y el impacto que han producido, estimulan a quien tenga un mínimo de interés por estas expresiones que constituyen una de las más importantes del ser humano.

A manera de conclusión, poniéndome en el contexto de los esfuerzos de integración producidos en todo el mundo en la actualidad, una de las preocupaciones de los países del Caribe, me atrevo a señalar que si bien para alcanzar una efectiva integración se requiere solucionar cuestiones medulares como la independencia, la democracia y la identidad y, sobre todo, la cooperación económica, a menudo se descuida un elemento primordial: la cultura, entendida esta en su acepción primigenia y esencial, que demanda una inmersión en la memoria de los pueblos, en sus expresiones más altas, en sus tradiciones originarias, en sus representantes más connotados, tal cual se encuentra en el diccionario sobre el Caribe, el excelente libro de Pedro Ureña Rib y Jean-Paul Duviols.

\section{Bibliografía}

Acosta, B., Goldeberg, S., y Sanz, I. (selección e introducción) (1977). Cuentos del Caribe. Barbados, Guyana, Jamaica. Trinidad-Tobago. La Habana: Casa de las Américas.
Amarante, H. (2009). Juan Bosch en el Perú. Lima: Consorcio Gráfico Global.

Burga Larrea, C. (1983). Diccionario geográfico e histórico de Cajamarca (toponimia departamental). Lima: Imprenta SAGSA.

Carew, J. (1982). Midas negro. La Habana: Casa de las Américas.

Díaz Varcárcel, E. (1966). El hombre que trabajó el lunes. México: Ediciones Era.

Fallas, C. L. (1972). Mamita Yunai. Santiago de Chile: Editorial Quimantú.

Gutiérrez, J. (1950). Puerto Limón. Santiago de Chile: Editorial Nascimiento.

Marán, R. (1945). Batuala. Buenos Aires: Ediciones Siglo veinte.

Naipaul, V. S. (1965). El curandero místico. Buenos Aires: Compañía General Fabril Editora.

Rhys, J. (1981). El vasto mar de los sargazos. La Habana: Casa de las Américas.

Roumain, J. (1971). Gobernadores del rocío. La Habana: Casa de las Américas.

Sinán, R. (1985). La isla mágica. La Habana: Casa de las Américas.

Stephen Alexis, J. (1969). En un abrir y cerrar de ojos. México: Ediciones Era.

Ureña Rib, P. y Duviols, J. (2014). El Caribe. Sus intelectuales, sus culturas, sus artistas, su historia, sus tradiciones populares. Santo Domingo: Editorial Santuario.

Recepción: 1-2-17

Aceptación: 1-3-17 